\title{
The Clarification of Low Friction Mechanism for Hydrogenated Amorphous Carbon by In-Situ Observation of Frictional Area
}

\author{
Hidenori Nishimura ${ }^{*}$, Noritsugu Umehara, Hiroyuki Kousaka and Xingrui Deng \\ Department of Mechanical Science and Engineering, Nagoya University \\ Furo-cho, Chikusa-ku, Nagoya, Aichi 464-8603, Japan \\ *Corresponding author: nishimura@ume.mech.nagoya-u.ac.jp \\ ( Manuscript received 18 August 2015; accepted 26 February 2016; published 30 April 2016) \\ (Presented at the International Tribology Conference Tokyo 2015, 16-20 September, 2015)
}

\begin{abstract}
Hydrogenated amorphous carbon $(\mathrm{a}-\mathrm{C}: \mathrm{H})$ coating which is one of carbonaceous coatings shows ultra low friction coefficient $(\mu<0.01)$ in dry Nitrogen gas. At present, it is expected to clarify low friction mechanism of a-C:H coating to apply a-C:H coating to industrial components. It was reported that hydrogen concentration, density, thickness and volume fraction of chemical bonds of surface layer (transformed layer) on bulk a-C:H coating during friction test were important to clarify low friction mechanism. But it is difficult to measure hydrogen concentration and density of transformed layer during friction test. In this study, we estimate the thickness and volume fractions of $\mathrm{C}-\mathrm{Csp}^{2}, \mathrm{C}-\mathrm{Csp}^{3}$ and $\mathrm{C}-\mathrm{H}$ bond of transformed layer during friction test by reflectance spectroscopy. In addition we calculate hydrogen concentration from volume fraction of $\mathrm{C}-\mathrm{H}$ bond and filling factor related to density of transformed layer during friction test. After friction test, surface energy of transformed layer is measured by sessile drop method. As a result, it is suggested that a-C:H coating shows low friction coefficient by reducing real contact area due to densification of transformed layer and repulsion force in hydrogen-terminated surface.
\end{abstract}

Keywords: a-C:H coating, low friction, transformed layer, in-situ observation, reflectance spectroscopy

\section{Introduction}

The carbonaceous coating is promising for high hardness, low friction property and affordability. Especially hydrogenated amorphous carbon (a-C:H) coating which is one of the carbonaceous coating is expected to low friction material in dry friction. Erdemir et al. reported that the friction coefficient decreased to 0.007 for the friction against a-C:H coating in dry Nitrogen gas [1]. Therefore it is expected to apply a-C:H coating to industrial components, and it is necessary to clarify low friction mechanism of a-C:H coating at present. Eldemir et al. also suggested a friction model that repulsive force from hydrogen-terminated surface on the coating reduced friction coefficient [1]. Racine et al. suggested that hydrogen atoms were migrated from internal layer to surface during friction test when a-C:H coating showed low friction coefficient [2]. Here we define the internal layer generated by friction as transformed layer. In addition, they suggested that density of the transformed layer below the hydrogen-terminated surface increased because of migration of hydrogen atoms [2]. From these reports, it is found that hydrogen concentration and density of transformed layer during friction test affect low friction coefficient of a-C:H coating. And in terms of low friction mechanism of other carbonaceous coatings, Ohara et al. reported that the thickness of low sharing strength layer on bulk amorphous carbon (a-C) coating affected friction coefficient by measuring thickness of transformed layer with reflectance spectroscopy after friction test when a-C coating slid with SUJ2 ball in PAO (Poly Alpha Olefin) oil [3]. Nishimura et al. estimated thickness and volume fractions of C-Csp ${ }^{2}, \mathrm{C}-\mathrm{Csp}^{3}$ and C-N bond in low sharing strength layer on bulk amorphous Carbon Nitride coating and suggested that thickness and hardness estimated by volume fraction of $\mathrm{C}-\mathrm{Csp}^{3}$ bond of the layer affected low friction coefficient in dry friction from in-situ observation of friction area by reflectance spectroscopy [4]. To summarize the above, we need to observe hydrogen concentration, density, thickness and volume fraction of chemical bonds of transformed layer during friction test to clarify low friction mechanism of a-C:H coating. But in these factors related to low friction, it is difficult to measure hydrogen concentration and density of transformed layer during friction test because there is no nondestructive method to measure hydrogen concentration and density of transformed layer. 
Therefore the in-situ measurement method of these parameters in transformed layer is needed to clarify low friction mechanism of a-C:H coating.

In this paper, we will introduce estimation methods of thickness and volume fractions of C-Csp ${ }^{2}, \mathrm{C}-\mathrm{Csp}^{3}$ and $\mathrm{C}-\mathrm{H}$ bond of transformed layer with a reflectance spectroscopy. And then we conduct friction test while estimating thickness and volume fractions of C-Csp ${ }^{2}$, $\mathrm{C}-\mathrm{Csp}^{3}$ and $\mathrm{C}-\mathrm{H}$ bond of transformed layer during friction test by reflectance spectroscopy. In addition we calculate hydrogen concentration of transformed layer from volume fraction of $\mathrm{C}-\mathrm{H}$ bond and filling factor related to density of transformed layer from volume fractions of C-Csp ${ }^{2}, \mathrm{C}-\mathrm{Csp}^{3}$ and $\mathrm{C}-\mathrm{H}$ bond during friction test. After friction test, estimate error of thickness and volume fractions of each bonds of transformed layer is calculated by using XPS (X-ray photoelectron spectroscopy) and AFM (Atomic Force Microscope) nano scratch test, and surface energy of transformed layer is quantified by measurement of contact angle of sessile drop by ESEM (Environmental Scanning Electron Microscope). Finally we will suggest low friction mechanism of a-C:H coating in dry friction.

\section{Experimental}

2.1. Estimation method for the thickness and bond fractions of transformed layer of a-C:H from optical properties

2.1.1 Estimation of thickness of transformed layer from optical properties

Thickness of the transformed layer of a-C:H coating can be estimated from reflectance $R$. Reflectance $R$ means the ratio of the reflected to incident light intensity. When a thin layer is deposited on a substrate, relationship between thickness of thin layer and optical constants is characterized by Eq. (1) to Eq. (5).

$$
\begin{aligned}
& R=\left|\frac{r_{01}+r_{12} \exp (-i 2 \beta)}{1+r_{01} r_{12} \exp (-i 2 \beta)}\right|^{2} \\
& \beta=\frac{2 \pi d N_{1}}{\lambda} \\
& r_{01}=\frac{N_{0}-N_{1}}{N_{0}+N_{1}} \\
& r_{12}=\frac{N_{1}-N_{2}}{N_{1}+N_{2}} \\
& N=n-i k
\end{aligned}
$$

where $d$ is thickness of thin layer, $\lambda$ is wavelength of light, $n$ is refractive index, $k$ is extinction coefficient, $\mathrm{N}_{2}$ is complex refractive index of substrate, $N_{1}$ is complex refractive index of thin layer and $N_{0}$ is complex refractive index of air. From these equations, one equation is made which unknowns are $d, n$ and $k$. If we know $n$ and $k$ of the coating, we can measure $d$ [5]. Therefore we estimated $n$ and $k$ by effective medium approximation which describe in the next section, then we estimated $d$ by using the estimated $n$ and $k$.
2.1.2 Estimation of volume fractions of C-Csp ${ }^{2}, \mathrm{C}-\mathrm{Csp}^{3}$ and $\mathrm{C}-\mathrm{H}$ bond in transformed layer from optical properties

J. Lee et al. reported that the effective medium approximation (EMA) which consists of C-Csp ${ }^{2}$ and $\mathrm{C}-\mathrm{Csp}^{3}$ in amorphous carbon coating was used to estimate $\mathrm{C}-\mathrm{Csp}^{3}$ fraction in amorphous carbon coating, the EMA showed a good monotonic correlation with those obtained by electron energy-loss spectroscopy (EELS) [6]. From this report, it is expected that we can estimate hydrogen concentrations of transformed layer from volume fraction of $\mathrm{C}-\mathrm{H}$ bond. In this time, when we suppose that optical property of a-C:H coating consists of optical properties of $\mathrm{C}-\mathrm{Csp}^{2}, \mathrm{C}-\mathrm{Csp}^{3}$ and $\mathrm{C}-\mathrm{H}$ bonds, relationship between optical property of a-C:H coating and volume fraction of $\mathrm{C}-\mathrm{H}$ bond is expressed by Eq. (6) and Eq. (7) [7].

$$
\begin{aligned}
0= & f_{\mathrm{C}-\mathrm{Csp}^{2}} \frac{\varepsilon_{\mathrm{C}-\mathrm{Csp}^{2}}-\varepsilon}{\varepsilon_{\mathrm{C}-\mathrm{Csp}^{2}}+2 \varepsilon} \\
& +f_{\mathrm{C}-\mathrm{Csp}^{3}} \frac{\varepsilon_{\mathrm{C}-\mathrm{Csp}^{3}}-\varepsilon}{\varepsilon_{\mathrm{C}-\mathrm{Csp}^{3}}+2 \varepsilon} \\
& +f_{\mathrm{C}-\mathrm{H}} \frac{\varepsilon_{\mathrm{C}-\mathrm{H}}-\varepsilon}{\varepsilon_{\mathrm{C}-\mathrm{H}}+2 \varepsilon} \\
1= & f_{\mathrm{C}-\mathrm{Csp}^{2}}+f_{\mathrm{C}-\mathrm{Csp}^{3}}+f_{\mathrm{C}-\mathrm{H}}
\end{aligned}
$$

where $f_{\mathrm{C}-\mathrm{Csp} 2}, f_{\mathrm{C}-\mathrm{Csp} 3}, f_{\mathrm{C}-\mathrm{H}}$ are volume fractions of C-Csp ${ }^{2}$, $\mathrm{C}-\mathrm{Csp}^{3}$ and $\mathrm{C}-\mathrm{H}$ bond and $\varepsilon, \varepsilon_{\mathrm{C}-\mathrm{Csp} 2}, \varepsilon_{\mathrm{C}-\mathrm{Csp} 3}, \varepsilon_{\mathrm{C}-\mathrm{H}}$ are complex dielectric constants of bulk a-C:H coating, $\mathrm{C}-\mathrm{Csp}^{2}, \mathrm{C}-\mathrm{Csp}^{3}$ and $\mathrm{C}-\mathrm{H}$ bond respectively.

Next $\varepsilon_{\mathrm{C}-\mathrm{Csp} 2}, \varepsilon_{\mathrm{C}-\mathrm{Csp} 3}$ and $\varepsilon_{\mathrm{C}-\mathrm{H}}$ are expressed by Eq. $(8)$ to Eq. (10).

$$
\begin{aligned}
\varepsilon_{\mathrm{C}-\mathrm{Csp}^{2}}= & \left(n_{\mathrm{C}-\mathrm{Csp}^{2}}{ }^{2}-k_{\mathrm{C}-\mathrm{Csp}^{2}}{ }^{2}\right) \\
& -i\left(2 n_{\mathrm{C}-\mathrm{Csp}^{2}} k_{\mathrm{C}-\mathrm{Csp}^{2}}\right) \\
\varepsilon_{\mathrm{C}-\mathrm{Csp}^{3}}= & \left(n_{\mathrm{C}-\mathrm{Csp}^{3}}^{2}-k_{\mathrm{C}-\mathrm{Csp}^{3}}{ }^{2}\right) \\
& -i\left(2 n_{\mathrm{C}-\mathrm{Csp}^{3}} k_{\mathrm{C}-\mathrm{Csp}^{3}}\right) \\
\varepsilon_{\mathrm{C}-\mathrm{H}}= & \left(n_{\mathrm{C}-\mathrm{H}}{ }^{2}-k_{\mathrm{C}-\mathrm{H}}{ }^{2}\right) \\
- & i\left(2 n_{\mathrm{C}-\mathrm{H}} k_{\mathrm{C}-\mathrm{H}}\right)
\end{aligned}
$$

where $n_{\mathrm{C}-\mathrm{Csp} 2}, n_{\mathrm{C}-\mathrm{Csp} 3}$ and $n_{\mathrm{C}-\mathrm{H}}$ are refractive index of $\mathrm{C}-\mathrm{Csp}^{2}$ bond, $\mathrm{C}-\mathrm{Csp}^{3}$ bond and $\mathrm{C}-\mathrm{H}$ bond respectively and $k_{\mathrm{C}-\mathrm{Csp} 2}, k_{\mathrm{C}-\mathrm{Csp} 3}$ and $k_{\mathrm{C}-\mathrm{H}}$ are extinction coefficient of $\mathrm{C}-\mathrm{Csp}^{2}$ bond, $\mathrm{C}-\mathrm{Csp}^{3}$ bond and $\mathrm{C}-\mathrm{H}$ bond respectively. If optical properties of C-Csp ${ }^{2}$ bond, C-Csp ${ }^{3}$ bond and $\mathrm{C}-\mathrm{H}$ bond are known, we can estimate $f_{\mathrm{C}-\mathrm{Csp} 2}, f_{\mathrm{C}-\mathrm{Csp} 3}$ and $f_{\mathrm{C}-\mathrm{H}}$ by numerical analysis. Moreover since dielectric constant consists of optical property of coating, we can estimate optical property of the coating from these volume fractions and Eq. (6). Therefore we can estimate thickness of the coating by using the estimated optical property. 


\subsection{Specimen}

a-C:H coating was deposited by PIG (Penning Ionization Gauge) plasma CVD (Chemical Vapor Deposition) method on Si (100) substrate. The thickness of a-C:H coating is about $1.0 \mu \mathrm{m}$. Hydrogen concentration of a-C:H coating is about 25 at.\%. Surface roughness $R_{\mathrm{a}}$ (arithmetic mean height) is $1.3 \mathrm{~nm}, R_{\mathrm{z}}$ (maximum height) is $13.7 \mathrm{~nm}$. And the hardness of a-C:H coating is $11.0 \mathrm{GPa}$.

\subsection{Apparatus}

Figure 1 shows friction tester with reflectance spectrometer FE-3000 made by Otsuka electric Co. Ltd. The reflectance spectrometer shined white light to a specimen, got the reflectance from the specimen. Reflectance $R$ is expressed by Eq. (11).

$$
R=\frac{I_{\text {ref }}}{I_{\text {int }}}
$$

where $I_{\text {ref }}$ and $I_{\text {int }}$ are intensity of reflected light and incident light respectively.

In this study, range of wavelength of incident light was $300 \mathrm{~nm}$ to $800 \mathrm{~nm}$, and measurement area was a circle of diameter about $10 \mu \mathrm{m}$. We set the reflectance spectroscopy above friction area, and we used sapphire hemisphere as a mating specimen which could transparent the visible light as a mating material of a-C:H coating. We conducted friction test under the sliding condition as $0.1 \mathrm{~N}$ of normal load and $400 \mathrm{rpm}$ of rotation speed of a-C:H coating. Dry Nitrogen gas was blown to frictional area during friction test, reflectance of a-C:H coating was measured by reflectance spectrometer every $200 \mathrm{rpm}$. And then we estimated thickness and $f_{\mathrm{C}-\mathrm{Csp} 2}$, $f_{\mathrm{C}-\mathrm{Csp} 3}$ and $f_{\mathrm{C}-\mathrm{H}}$ in transformed layer from the results of reflectance. From $f_{\mathrm{C}-\mathrm{Csp} 2}, f_{\mathrm{C}-\mathrm{Csp} 3}$ and $f_{\mathrm{C}-\mathrm{H}}$ in each sliding cycles, filling factors of transformed layer were calculated. Filling factor in this paper is expressed by Eq. (12) $[8]$.

$$
\begin{aligned}
f= & \frac{12 \rho}{12\left(f_{\mathrm{C}-\mathrm{Csp}^{2}}+f_{\mathrm{C}-\mathrm{Csp}^{3}}\right)+f_{\mathrm{C}-\mathrm{H}}} \\
& \times\left(\frac{f_{\mathrm{C}-\mathrm{Csp}^{2}}}{2.26}+\frac{f_{\mathrm{C}-\mathrm{Csp}^{3}}}{3.51}+\frac{f_{\mathrm{C}-\mathrm{H}}}{3.51}\left(\frac{37}{77}\right)^{3}\right)
\end{aligned}
$$

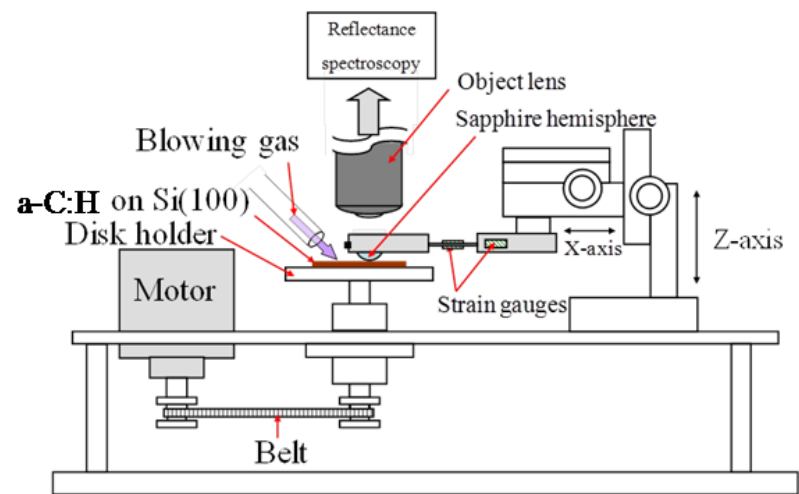

Fig. 1 Schematic of pin-on-disk friction tester with reflectance spectrometer where $\rho$ is density of transformed layer in certain sliding cycles. In this paper, we estimated $\rho$ from refractive index of transformed layer calculated by reflectance spectroscopy because refractive index was related to density [9].

After friction test, AFM nano scratch test was conducted to measure hardness and thickness of transformed layer. We measured scratch depth after every scratch, and we measured rate of change of each scratch depth. Then we calculated the hardness of transformed layer by comparing to the rate of change of out and inside of wear scar, respectively [10,11].

And we measured C1s spectrum of transformed layer by XPS. We divided $\mathrm{C} 1 \mathrm{~s}$ peak into two peaks. One was a peak of $\mathrm{C}-\mathrm{Csp}^{2}$ bond and the other was a combined peak of C-Csp ${ }^{3}$ and C-H bond [12]. And we calculated an area proportion of peak of $\mathrm{C}-\mathrm{Csp}^{2}$ bond to all bonds as $f_{\mathrm{C}-\mathrm{Csp} 2}$ and an area proportion of combined peak of $\mathrm{C}-\mathrm{Csp}^{3}$ and $\mathrm{C}-\mathrm{H}$ bonds to all bonds as $f(\mathrm{C}-\mathrm{Csp} 3+\mathrm{C}-\mathrm{H})$. To evaluate accuracy of $f_{\mathrm{C}-\mathrm{Csp} 2}, f_{\mathrm{C}-\mathrm{Csp} 3}$ and $f_{\mathrm{C}-\mathrm{H}}$ by reflectance spectroscopy, we compared $f_{\mathrm{C}-\mathrm{Csp} 2}$ and $f(\mathrm{C}-\mathrm{Csp} 3+\mathrm{C}-\mathrm{H})$ by XPS analysis to those by reflectance spectroscopy.

And we measured contact angles of sessile drops of water and diiodomethane on surface from ESEM observation. Then hydrogen bonding force component and dispersion force component in surface energy was measured from contact angle of sessile drops respectively $[13,14]$.

\section{Results}

3.1. Variation of thickness of transformed layer and friction coefficient with number of sliding cycles

Figure 2 shows relationship between friction coefficient and thickness of transformed layer as a function of sliding cycles. Friction coefficient reduced to 0.02 at the end of sliding cycles (10000 cycles). $R_{\mathrm{z}}$ inside of wear scar was $3.0 \mathrm{~nm}$ by AFM. Thickness of transformed layer was calculated from section 2.1.1. And the range of wavelength to calculate the thickness was from $300 \mathrm{~nm}$ to $500 \mathrm{~nm}$. From Fig. 2, transformed layer was generated from 200 cycles. Thickness of transformed layer at 10000 cycles was $15.8 \mathrm{~nm}$.

3.2. Variation of $f_{\mathrm{C}-\mathrm{Csp} 2}, f_{\mathrm{C}-\mathrm{Csp} 3}$ and $\mathrm{fC}-\mathrm{H}$ of transformed layer and friction coefficient with number of sliding cycles

Figure 3 to 5 show $\varepsilon_{\mathrm{C}-\mathrm{Csp} 2}, \varepsilon_{\mathrm{C}-\mathrm{Csp} 3}$ and $\varepsilon_{\mathrm{C}-\mathrm{H}}$ as a function of light wavelength $300 \mathrm{~nm}$ to $800 \mathrm{~nm}$. Each dielectric constants was calculated from section 2.1.2. And we defined real part of $\varepsilon_{\mathrm{C}-\mathrm{Csp} 2}$ as $R_{\mathrm{e}}\left(\varepsilon_{\mathrm{C}-\mathrm{Csp} 2}\right)$ and imaginary part of $\varepsilon_{\mathrm{C}-\mathrm{Csp} 2}$ as $I_{\mathrm{m}}\left(\varepsilon_{\mathrm{C}-\mathrm{Csp} 2}\right)$, real part of $\varepsilon_{\mathrm{C}-\mathrm{Csp} 3}$ as $R_{\mathrm{e}}\left(\varepsilon_{\mathrm{C}-\mathrm{Csp} 3}\right)$ and imaginary part of $\varepsilon_{\mathrm{C}-\mathrm{Csp} 3}$ as $I_{\mathrm{m}}\left(\varepsilon_{\mathrm{C}-\mathrm{Csp} 3}\right)$ and real part of $\varepsilon_{\mathrm{C}-\mathrm{H}}$ as $R_{\mathrm{e}}\left(\varepsilon_{\mathrm{C}-\mathrm{H}}\right)$ and imaginary part of $\varepsilon_{\mathrm{C}-\mathrm{H}}$ as $I_{\mathrm{m}}\left(\varepsilon_{\mathrm{C}-\mathrm{H}}\right)$, respectively. From Eq. (6) and Fig. 3 to Fig. $5, f_{\mathrm{C}-\mathrm{Csp} 2}, f_{\mathrm{C}-\mathrm{Csp} 3}$ and $f_{\mathrm{C}-\mathrm{H}}$ of transformed layer can be estimated by optical properties of transformed layer with reflectance spectrometer. And the range of wavelength to estimate volume fractions was from $300 \mathrm{~nm}$ to 500 


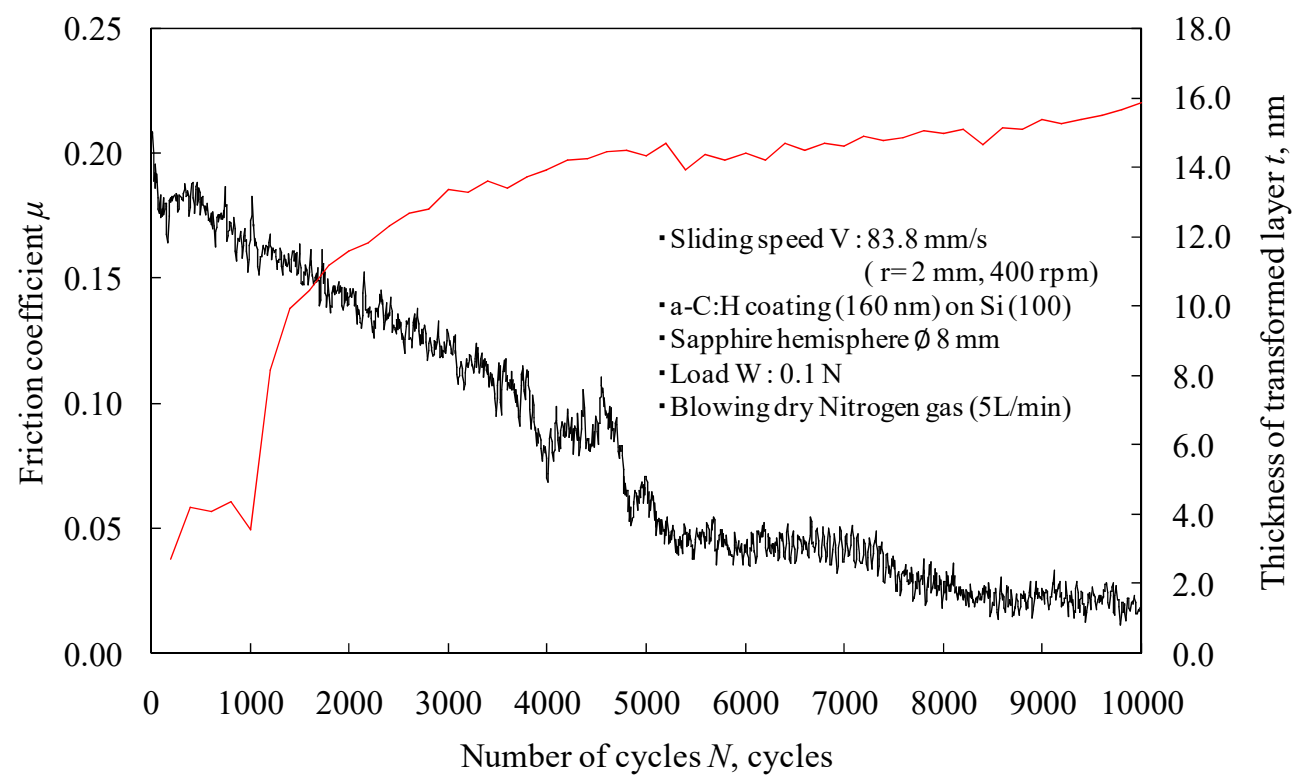

Fig. 2 Friction coefficient and thickness of transformed layer sliding as a function of sliding cycles

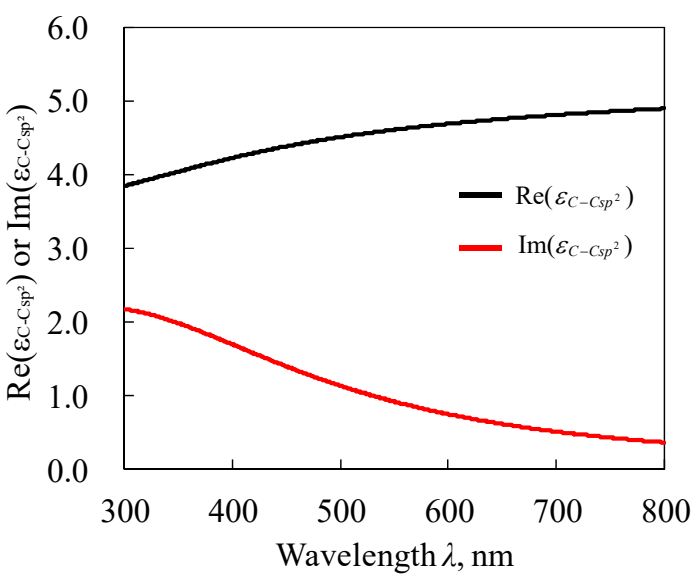

Fig. 3 Dielectric constant of C-Csp ${ }^{2}$ bond

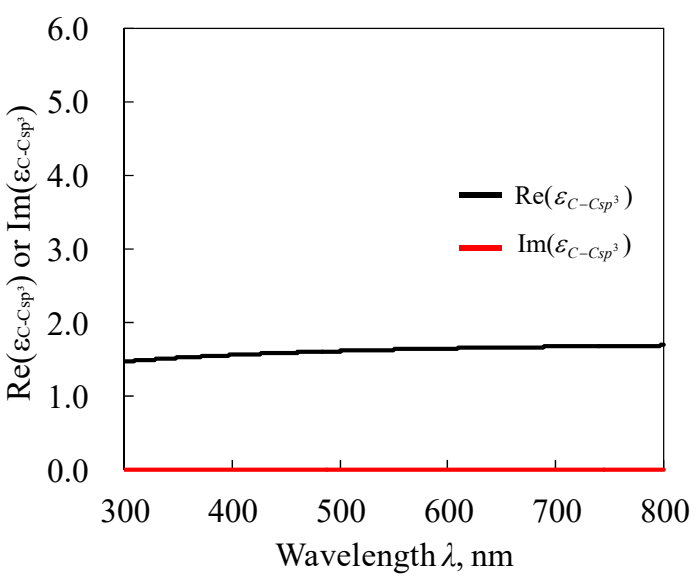

Fig.4 Dielectric constant of C-Csp ${ }^{3}$ bond

$\mathrm{nm}$. Figure 6 shows relationship between friction coefficient and $f_{\mathrm{C}-\mathrm{Csp} 2}, f_{\mathrm{C}-\mathrm{Csp} 3}$ and $f_{\mathrm{C}-\mathrm{H}}$ as a function of sliding cycles. From Fig. $6, f_{\mathrm{C}-\mathrm{Csp} 2}, f_{\mathrm{C}-\mathrm{Csp} 3}$ and $f_{\mathrm{C}-\mathrm{H}}$ of transformed layer at 10000 cycles was $0.719,0.096$ and 0.185 , respectively.

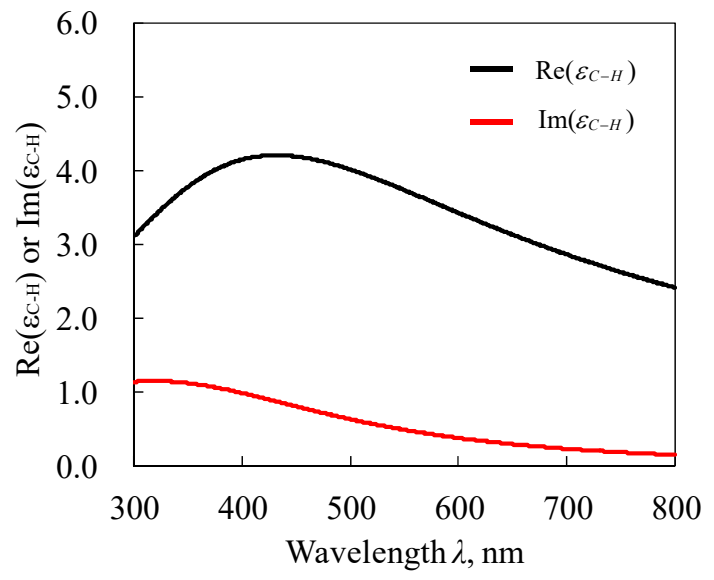

Fig. 5 Dielectric constant of C-H bond

3.3. Variation of filling factor of transformed layer and friction coefficient with number of sliding cycles

Figure 7 shows relationship between friction coefficient and filling factor as a function of sliding cycles. Filling factor increased from 0.64 at 200 cycles to 0.78 at 10000 cycles during friction test.

3.4. Variation of scratch depth of inside and out of wear scar with number of scratch cycles

Figure 8 shows that scratch depth of out of wear scar and inside of wear scar by AFM nano scratch test as a function of scratch cycles. The rate of change of each scratch depth in wear scar changed after 7 th scratch. Since the scratch depth of transformed layer was 16.0 $\mathrm{nm}$ after 7 th scratch, thickness of transformed layer was supposed to be $16.0 \mathrm{~nm}$. Additionally, wear depth of transformed layer per one scratch was $2.28 \mathrm{~nm}$, and that of out of wear scar was $4.03 \mathrm{~nm}$ until 7 th scratch cycles. Since hardness of as-deposited a-C:H coating is 11.0 $\mathrm{GPa}$, hardness of transformed layer was supposed to be $19.4 \mathrm{GPa}[10,11]$. 


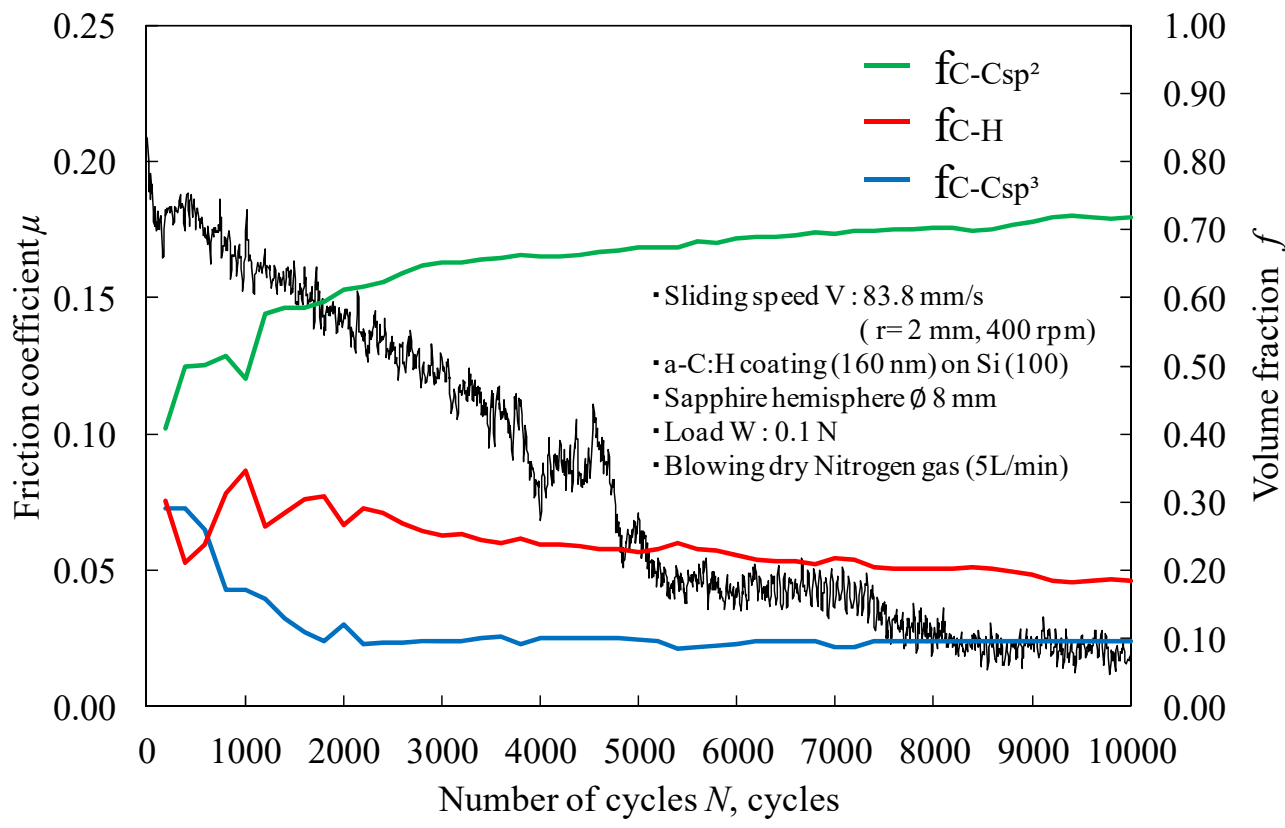

Fig. 6 Friction coefficient and volume fractions of C-Csp ${ }^{2}, \mathrm{C}-\mathrm{Csp}{ }^{3}$ and $\mathrm{C}-\mathrm{H}$ bond of transformed layer sliding as a function of sliding cycles

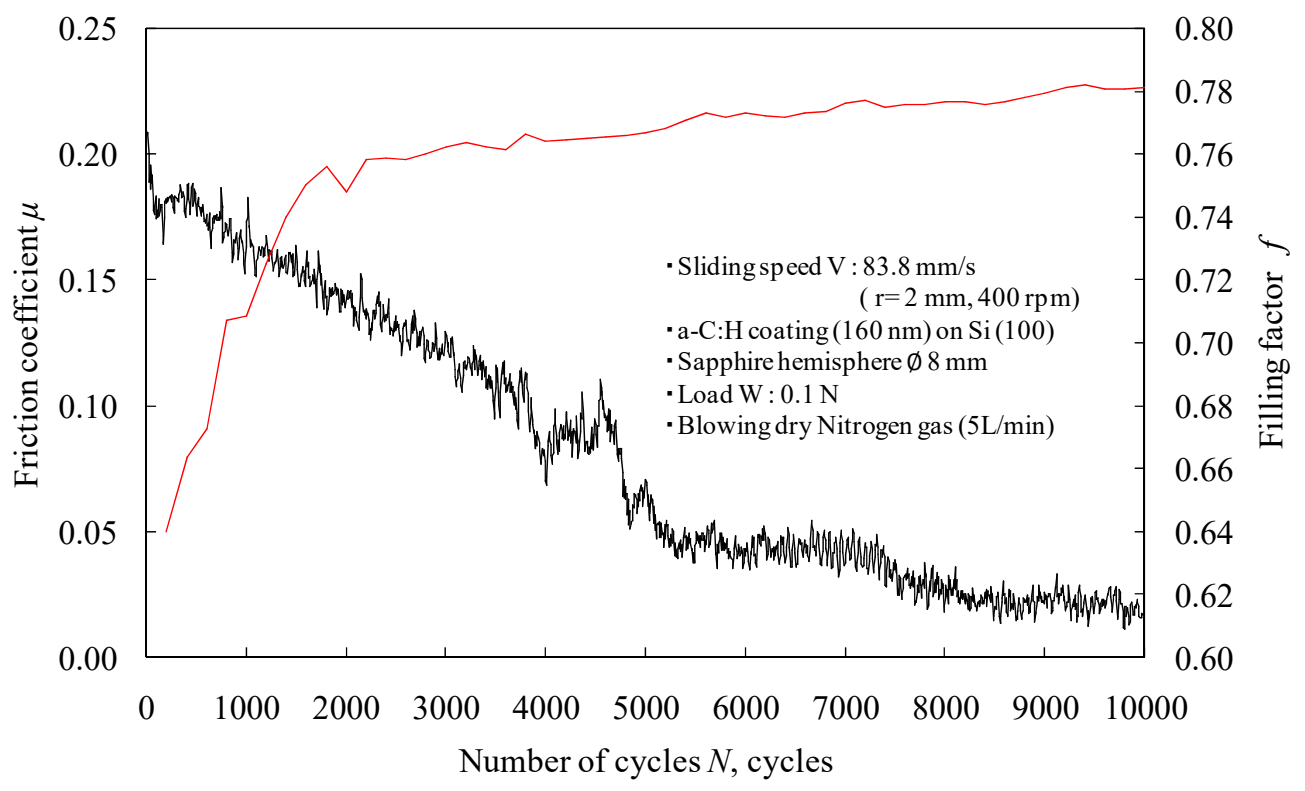

Fig. 7 Friction coefficient and filling factor of transformed layer sliding as a function of sliding cycles

3.5. $f_{\mathrm{C}-\mathrm{Csp} 2}$ and $f(\mathrm{C}-\mathrm{Csp} 3+\mathrm{C}-\mathrm{H})$ of transformed layer by XPS and reflectance spectroscopy

Figure 9 shows $\mathrm{C} 1 \mathrm{~s}$ spectrum of transformed layer by XPS analysis. From Fig. 9, $f_{\mathrm{C}-\mathrm{Csp} 2}$ is measured to 0.71 and $f(\mathrm{C}-\mathrm{Csp} 3+\mathrm{C}-\mathrm{H})$ is measured to 0.29 by XPS analysis. And from Fig. 6 and section $3.2, f_{\mathrm{C}-\mathrm{Csp} 2}$ and $f\left({ }_{\mathrm{C}-\mathrm{Csp} 3}+\mathrm{C}-\mathrm{H}\right)$ of transformed layer at 10000 cycles were 0.719 and 0.281 by reflectance spectroscopy, respectively.

3.6. Variation of surface energy of inside and out of wear scar by ESEM

Figure 10 shows contact angle of sessile drops of water and diiodomethane formed on out of wear scar and inside of wear scar respectively. And Fig. 11 shows surface energy of out of wear scar and inside of wear scar respectively. Hydrogen bonding force component of transformed layer decreased $3.0 \mathrm{~mJ} / \mathrm{m}^{2}$ compared to that of out of wear scar. And dispersion force component of transformed layer decreased $6.0 \mathrm{~mJ} / \mathrm{m}^{2}$ compared to that of out of wear scar.

\section{Discussion}

4.1. Evaluation of error of estimations for thickness, $f_{\mathrm{C}-\mathrm{Csp} 2}, f_{\mathrm{C}-\mathrm{Csp} 3}$ and $f_{\mathrm{C}-\mathrm{H}}$ of transformed layer by 


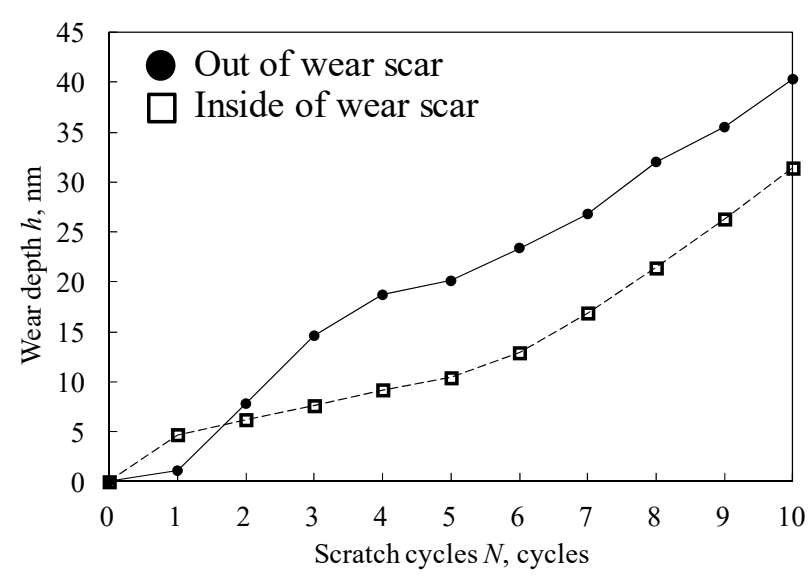

Fig. 8 Scratch depth of out of wear scar and inside of wear scar by AFM nano scratch test as a function of scratch cycles

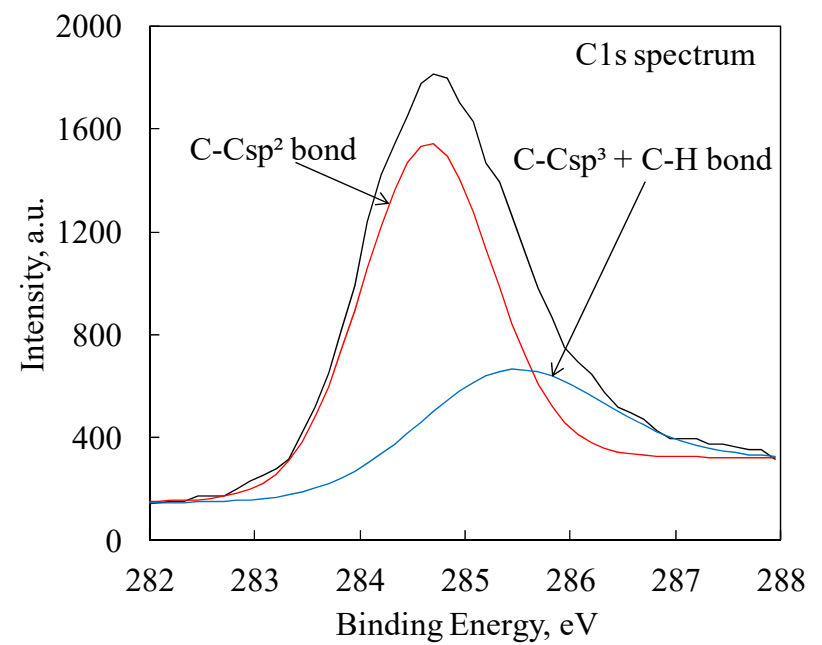

Fig. 9 C1s spectrum of transformed layer by XPS analysis

reflectance spectroscopy

From Fig. 2, thickness of transformed layer at 10000 cycles was $15.8 \mathrm{~nm}$ by reflectance spectroscopy and 16.0 $\mathrm{nm}$ by AFM nano scratch, respectively. From this result, reflectance spectroscopy enables us to estimate thickness of transformed layer within a tolerance of $1.3 \%$.

From Fig. 6, Fig. 9 and section 3.5, $f_{\mathrm{C}-\mathrm{Csp} 2}, f_{\mathrm{C}-\mathrm{Csp} 3}$ and $f_{\mathrm{C}-\mathrm{H}}$ can be estimated within a tolerance of $1.0 \%$ by reflectance spectroscopy.

4.2. Suggestion of low friction mechanism of a-C:H coating with blowing dry Nitrogen gas

Next we consider low friction mechanism of a-C:H coating from results. We suggested that the reasons why $\mathrm{a}-\mathrm{C}: \mathrm{H}$ coating showed low friction were reduction of real contact area and generation of repulsive force at surface of wear scar. First, we considered how real contact area reduced. From section 3.4., hardness of transformed layer was higher than that of as-deposited a-C:H coating. From Fig. 7, filling factor of transformed layer increased with decreasing of friction coefficient. And volume fractions of $\mathrm{C}-\mathrm{H}$ bond in transformed layer

Japanese Society of Tribologists (http://www.tribology.jp/)

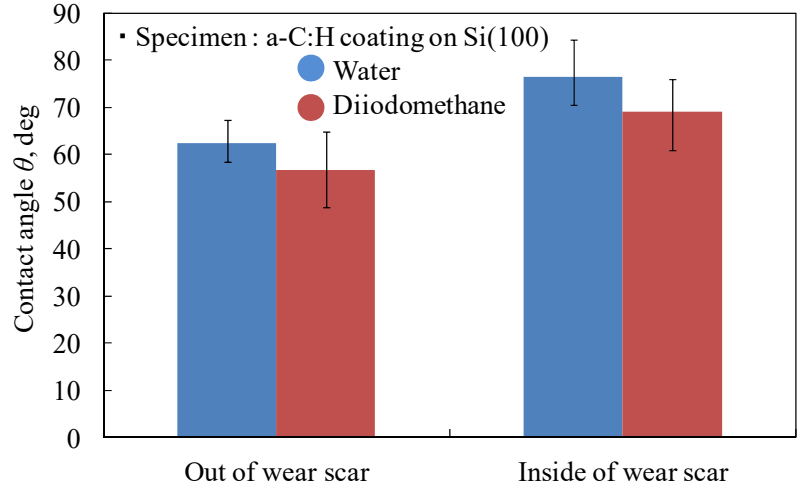

Fig. 10 Contact angle of sessile drops formed on out of wear scar and inside of wear scar

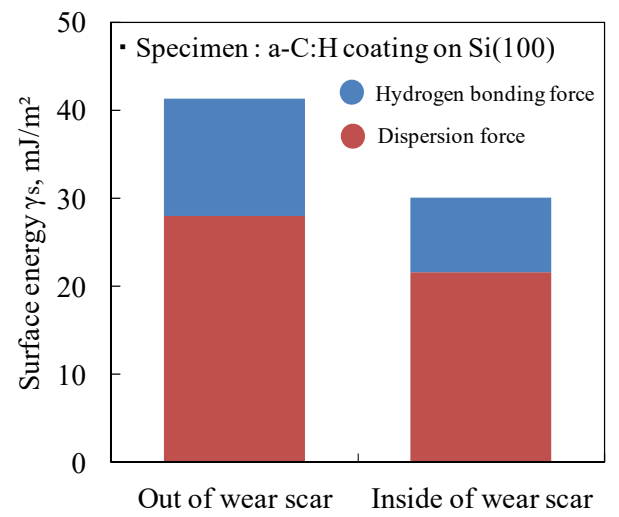

Fig. 11 Surface energy of out of wear scar and inside of wear scar

decreased with decreasing of friction coefficient from Fig. 6. From these results and Racine's report, it is thought that increasing density of transformed layer by reducing $\mathrm{C}-\mathrm{H}$ bonds increased hardness of transformed layer [2]. That is the reason why real contact area reduced. Second, we considered how repulsive force was generated at the surface of wear scar. From Fig. 11, hydrogen bonding force inside of wear scar decreased compared to that out of wear scar. That means surface of transformed layer gets hydrophobic. From Eldemir's report, it is thought that there is hydrogen-terminated surface on transformed layer because $\mathrm{C}-\mathrm{H}$ bond is hydrophobic, and then the repulsive force was generated at the surface [1]. That is the reason why repulsive force was generated at the surface of wear scar.

\section{Conclusion}

To clarify low friction mechanism of a-C:H coating in dry Nitrogen gas, we estimated thickness, $f_{\mathrm{C}-\mathrm{Csp} 2}$, $f_{\mathrm{C}-\mathrm{Csp} 3}$ and $f_{\mathrm{C}-\mathrm{H}}$ and filling factor of transformed layer on bulk a-C:H coating during friction test by reflectance spectroscopy. We confirmed that these estimations were in good agreement with result by XPS and AFM nano scratch test. Obtained main results are following.

(1) $f_{\mathrm{C}-\mathrm{H}}$ of transformed layer was lower and filling factor of transformed layer was larger than bulk a-C:H coating after repeated sliding.

Tribology Online, Vol. 11, No. 2 (2016) / 346 
(2) Surface energy of inside of wear scar decreased compared to out of wear scar by the measurement of contact angle of sessile drop with ESEM.

(3) Results suggested that the reasons why a-C:H coating showed low friction were reduction of real contact area and generation of repulsive force at the surface of wear scar.

\section{Acknowledgement}

This paper was supported by Grant-in-Aid for Scientific Research (25220902). I appreciate this support.

\section{References}

[1] Erdemir, A., "The Role of Hydrogen in Tribological Properties of Diamond-Like Carbon Films," Surface and Coatings Technology, 146-147, 2001, 292-297.

[2] Racine, B., Benlahsen, M., Zellama, K., Zarrabian, M., Villain, J. P., Turban, G. and Grosman, A., "Hydrogen Stability in Diamond-Like Carbon Films During Wear Tests," Applied Physics Letters, 75, 22, 1999, 3479-3481.

[3] Ohara, K., Masripan, N. A., Umehara, N., Kousaka, H., Tokoroyama, T., Inami, S., Zushi, K. and Fujita, M., "Evaluation of Transformed Layer of DLC Coatings After Sliding in Oil Using Spectroscopic Reflectometry," Tribology International, 65, 2013, 270-277.

[4] Nishimura, H., Umehara, N., Kousaka, H. and Tokoroyama, T., "Clarification of Relationship between Friction Coefficient and Transformed Layer of $\mathrm{CN}_{x}$ Coating by In-Situ Spectroscopic Analysis," Tribology International, 93, Part B, 2016, 660-665.

[5] Azzam, R. M. A. and Bashara, N. M., "Ellipsometry and Polarized Light," Elsevier, North-Holland, 1987.

[6] Lee, J., Collins, R. W., Veerasamy, V. S. and Robertson, J., "Analysis of Amorphous Carbon
Thin Films by Spectroscopic Ellipsometry," Journal of Non-Crystalline Solids, 227-230, 1, 1998, 617-621.

[7] Aspnes, D. E., "Optical Properties of Thin Films," Thin Solid Films, 89, 3, 1982, 249-262.

[8] Jiang, X., Reichelt, K. and Stritzker, B., "Mechanical Properties of a-C:H Films Prepared by Plasma Decomposition of $\mathrm{C}_{2} \mathrm{H}_{2}$," Journal of Applied Physics, 68, 3, 1990, 1018-1022.

[9] Feynman, R. P., Leighton, R. B. and Sands, M. L., "The Feynman Lectures on Physics II Mainly Electromagnetic and Matter," Addison Wesley Longman, 1970.

[10] Kimura, N., Tsukiyama, Y., Tokoroyama, T. and Umehara, N., "Evaluation of Mechanical Properties of the Superficial Layer of $\mathrm{CN}_{x}$ with Ultra Low Friction in $\mathrm{N}_{2}$ Gas," Transactions of the Japan Society of Mechanical Engineers, Series C, 76, 772, 2010, 612-617 (in Japanese).

[11] Masripan, N. A. B., Tsukiyama, Y., Ohara, K., Umehara, N., Kousaka, H., Tokoroyama, T, Inami, S., Zushi, K. and Fujita, M., "Evaluation of Transformed Layer of DLC Coating After Friction Test using Atomic Force Microscopy (AFM)," Proceedings of Malaysian International Tribology Conference 2015, Penang, 2015, 32-33.

[12] Tokoroyama, T., Hatano, T., Umehara, N. and Fuwa, Y., "The Effect of Ultraviolet Light Irradiation on Tribological Properties of Hydrogenated DLC," 2010 International Symposium on Micro-NanoMechatronics and Human Science (MHS), Nagoya, 2010, 234-238.

[13] Owens, D. K. and Wendt, R. C., "Estimation of the Surface Free Energy of Polymers," Journal of Applied Polymer Science, 13, 8, 1969, 1741-1747.

[14] Umehara, N., Yamaguchi, Y. and Kato, K., "New Evaluation Method for Surface Energy with mm Size Liquid Droplets," Proceeding of International Symposium For High Performance of Tribosystem, Daegu, 2001, 17-21. 